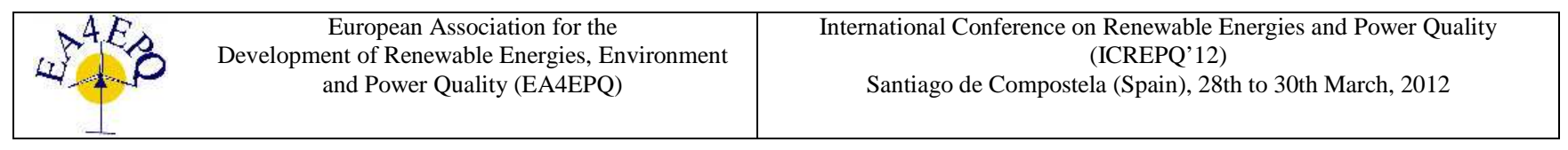

\title{
Experimental and theoretical analysis of thermal solar collector systems for DHW in Northern Italy
}

\author{
Arboit, M. ${ }^{2}$; Toniolo, J. ${ }^{1}$; Ghafoor, A. ${ }^{1}$ and Fracastoro, G.V. ${ }^{1}$ \\ ${ }^{1}$ Energy Department, Politecnico di Torino. Corso Duca degli Abruzzi 24, 10129 Torino, Italy \\ ${ }^{2}$ Instituto de Ciencias Humanas, Sociales y Ambientales (INCIHUSA-CONICET), Adrián Ruiz Leal s/n, Parque General \\ San Martín, 5500 Mendoza, Argentina- marboit@mendoza-conicet.gov.ar
}

\begin{abstract}
The aim of this work is to describe a methodology for the in situ experimental evaluation of the performance of Solar Collector systems for Domestic Hot Water production (SCDHW), which are by far the most common use of solar thermal collectors. In situ monitoring of ten SCDHW, including DHW storage and back-up heating system led to an estimate of yearly performance, which has been compared with results from simulations performed using widely spread commercial software and $f$ - chart method. Measurements were carried out for at least 20 days for each plant, with sampling rate of ten minutes. As DHW demand was unknown, it was assumed from SC area. Results show that the solar collector's area was systematically oversized respect to actual DHW needs, resulting in measured lower efficiency (around 30\%) than calculated by commercial software. Reducing DHW needs, measurements and calculations produced closer results.
\end{abstract}

Key words: thermal solar collector systems, solar energy, energy efficiency.

\section{Introduction}

Although the European solar thermal market has experienced for the second year running an overall decrease in 2010, it still remains above its 2007 level with a total of 2586 MWth $\left(3694940 \mathrm{~m}^{2}\right)$ of newly installed capacity. This is mainly due to the decrease of Germany ($29 \%$ ), the largest European market.

On the other hand, Italy has recently become, after years of apparent lack of interest, the second European Country in terms of new installed Solar Thermal Systems (13\%), and has maintained in 2010 its 2009 level with $343000 \mathrm{~kW}_{\text {th }}$ $\left(490000 \mathrm{~m}^{2}\right)$.

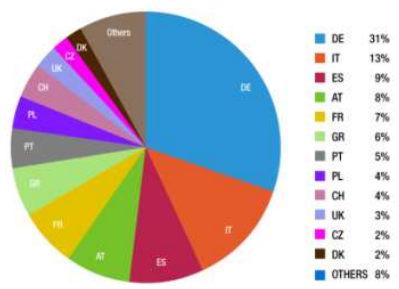

Fig. 1: Shares of the European Solar Thermal Market in 2010 (Newly Installed Capacity) [1]
Renewable energy installations are characterized by a savings over investments ratio, which is often not very favourable. This ratio is the value used in policy decision making of economic investment to provide a decrease of emission with the least amount of money. It is clear that those values are reliable if the installed systems are working as expected. Thermal systems are often poorly monitored and their actual production is often unknown. For small investments, as SCDHW systems are, it is really hard to obtain reliable performance data, even if solar collectors performance is evaluated according to some established standards, such as EN 12976 and ISO 9806 [2],[3]. Public bodies consider sufficient to control if the system was actually installed or not, but not if the system is working properly. An analysis of SCDHW working conditions should be made by end users but, due to the presence of back-up heating system, even if solar collectors are idle, the system will provide DHW. The end users will not be aware of any malfunctioning of the system while it is still providing hot water.

Also detecting malfunctioning by energy cost analysis is difficult, because other energy uses are connected to the same gas meter (or electric meter as well). One of the systems analyzed had the solar collectors out of service, but neither the end users neither the maintenance company had notice of that.

The previous example implies that public bodies have no knowledge if the investments in SCDHW system are really helping in reducing emissions and that end users/maintenance companies are not able to ensure that system is working. A methodology is therefore needed to control and evaluate the performance of SCDHW systems.

The present work carried out ten detailed inspections and data monitoring campaigns, in order not only to evaluate SCDHW systems efficiency, but if possible also to suggest a standard methodology for SCDHW evaluation. Short timing, low cost inspection and reliability of results are addressed.

\section{Methodology}

A common evaluation methodology has been developed to determine from a short period measurement campaign (2-3 weeks) the predicted annual energy production and 
to identify the cause of malfunctioning problems that cannot be identified through visual assessment in-situ.

The evaluation methodology consisted in three phases:
A. Inspection
B. Monitoring
C. Simulation

In table I the different case studies and the characteristics of the installations can be observed.

Table I. Case Studies

\begin{tabular}{|l|l|l|c|l|}
\hline $\mathbf{N}^{\mathbf{0}}$ & $\mathbf{m}^{\mathbf{2}}$ & \multicolumn{1}{|c|}{ Use } & Type & \multicolumn{1}{|c|}{ Architectural Typology } \\
\hline 1 & 6.6 & Daycare center & FP & semi integrated on the roof slope \\
\hline 2 & 11.1 & $\begin{array}{l}\text { Dining hall of a } \\
\text { School }\end{array}$ & FP & semi integrated on the roof slope \\
\hline 3 & 5.6 & Daycare center* & VT & Installed on a flat roof \\
\hline 4 & 30.6 & $\begin{array}{l}\text { Sports Club/ } \\
\text { Gymnasium }\end{array}$ & FP & semi integrated on the roof slope \\
\hline 5 & 33.2 & Swimming Pool & VT & Installed on a flat roof \\
\hline 6 & 7.1 & $\begin{array}{l}\text { Camping } \\
\text { Showers }\end{array}$ & FP** & Installed on the ground \\
\hline 7 & 4.0 & $\begin{array}{l}\text { Daycare center } \\
\text { Kitchen }\end{array}$ & FP & semi integrated on the roof slope \\
\hline 8 & 18.8 & Daycare center & FP & semi integrated on the roof slope \\
& & & FP & Installed on a flat roof \\
\hline 9 & 21.0 & Gymnasium & VT & Installed on a flat roof \\
\hline 10 & 17.8 & Sports Club & glass plane. VT: Vacuum Tube. \\
\hline
\end{tabular}

\section{Inspection and Monitoring}

\section{A. Inspection}

This work is aimed to test a methodology in order to verify that the solar part of a DHW installation operates correctly and coherently with the design.

The inspection has been structured in the following stages:

- Survey and inspection of the installations: interview with the person in charge so as to gather information about the installations functioning and maintenance, obtain the project plans, and be informed regarding the technical documentation with specifications about the planned supply of DHW to the building.

- Installation Operation Control: verification of equipment and correct functioning of all the system components. Verification of the solar control system

- Development of a simple format including the conclusions after the inspection stage and a report of the main characteristics of the system:

- Installation Site

- Type, brand, model, number and net area of the collectors

- Orientation and tilt of the collectors

- Brand and model of the control system

- Brand, model and volume of the storage tank

- Installation and functioning scheme

- Programming parameters for the control system (storage and circulation temperature)

- Installation and technical design coherence

\section{B. Monitoring}

The minimum monitoring period was established in 15 days and the sampling time of the relevant quantities was ten minutes. During the monitoring period the input $\left(\mathrm{T}_{\text {in }}\right)$ output $\left(\mathrm{T}_{\text {out }}\right)$ temperatures and the flow rate through the solar circuit at the storage tank have been recorded.

In the cases in which there were external heat exchangers between the collectors and the storage, the measurement has been carried out over the primary (solar) circuit of the exchanger.

The measurement apparatus included:

- Ultrasonic flow meter

- Temperature probes

- Pump monitoring data logger

- Solarimeter

\section{Heat power measurement}

The surveyed data have been used to calculate the useful power produced by the solar system:

$\mathrm{P}_{\mathrm{u}}=\dot{\mathrm{m}} \mathrm{c}_{\mathrm{p}}\left(\mathrm{T}_{\text {out }}-\mathrm{T}_{\mathrm{in}}\right)$

The ultrasonic flow meter is a non-intrusive sensor requiring as inputs the cross section area and fluid density. The fluid speed is measured above $0.1 \mathrm{~m} / \mathrm{s}$ and with $\pm 3 \%$ accuracy.

The temperature probes are type $\mathrm{K}$ thermocouples, calibrated at the Department laboratory. They were placed at the inlet and outlet of the solar installation.

Parallel to the flow measurement the pump functioning has been verified with a "status" data logger.

The flow meter was installed during the first days of monitoring. It has been verified that the flow was stable and constant, so, once this was known, it could be replaced by only the "status" recorder, with an error below $2 \%$, the same order of magnitude of the flow meter error. As a consequence, the flow meter has only been used during the first 60 minutes in the first inspection day, and was later replaced by the status data logger.

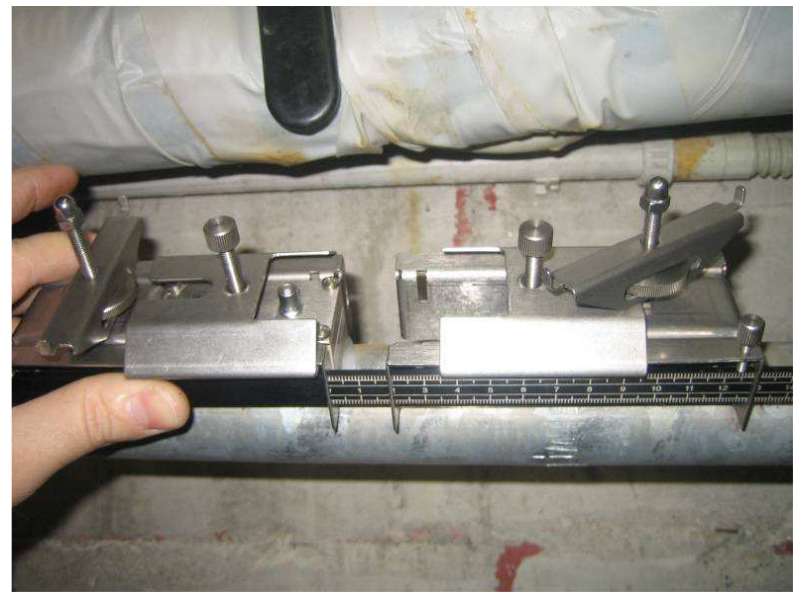

Fig. 2. Installation of flow meter

Available solar energy on solar thermal collectors has been calculated from solar irradiance measurements available at Politecnico, considering the tilt and azimuth of solar panels. 


\section{Simulation}

Average efficiency: The first simulation of the yearly performance of the installations has been made assuming that the ratio between useful energy produced and available energy during the measurement period, remains constant over the year.

$\mathrm{E}_{\mathrm{u}}=\bar{\eta} \mathrm{E}_{\mathrm{s}}$

Where:

$\mathrm{E}_{\mathrm{u}}=$ Useful energy produced ( $\mathrm{kWh} /$ day)

$\mathrm{E}_{\mathrm{s}}=$ Available solar energy onto the collector plane (kWh/day)

$\bar{\eta}=$ Daily average solar system efficiency

The performance value obtained during the measurement period has been extrapolated to the annual period using typical climatic data provided by Italian standard UN10349.

In order to produce more accurate yearly predictions two simple theoretical models have been developed.

Model A: consists in making a linear regression between daily energy available onto the collector's plane and the daily energy produced during the measurement period.

$$
\mathrm{E}_{\mathrm{u}}=\mathrm{a}+\mathrm{b} \mathrm{E}_{\mathrm{s}}
$$

Where;

$\mathrm{E}_{\mathrm{u}}=$ Useful energy produced ( $\mathrm{kWh} /$ day)

$\mathrm{E}_{\mathrm{s}}=$ Available solar energy onto the collector plane (kWh/day)

$\mathrm{a}, \mathrm{b}=$ Linear regression coefficients.

In Figure 3 an example of the correlation, in reference to Case Study 1, can be observed.

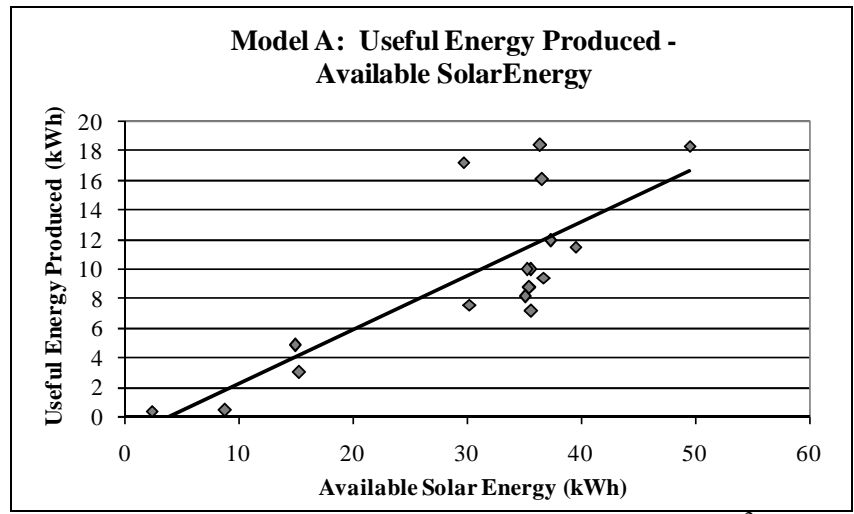

Fig. 3. Model A: Intercept $y=-1.476 \mathrm{kWh}$. Slope $=0.37$. $\mathrm{R}^{2}=0.64$

The regression is characterized by a generally acceptable linear correlation (0.6-0.8), even if the model does not take directly into account the outdoor temperature.

A negative intersection of the straight line (coefficient "a") has always been recorded except for case $n^{\circ} 5$. It may be interpreted as the minimum energy necessary to "activate" the system, coherently with the control system logics, which will switch on the pump as a function of the temperature difference between the collector and the storage.

Model B: The model assumes that the average system performance is a function of $\mathrm{x}$, the variable typically used to calculate the performance of solar collectors, as in the standard UNI-EN-12976.

$\mathrm{E}_{\mathrm{u}}=\eta \mathrm{E}_{\mathrm{s}}$ where $\eta=\mathrm{a}+\mathrm{bx}$

and

$x=\frac{\bar{T}_{c}-\bar{T}_{a}}{\left(H / h_{\text {sun }}\right)}=\frac{\bar{T}_{c}-\bar{T}_{a}}{\bar{G}}$

Where;

$\overline{\mathrm{T}}_{\mathrm{c}}=$ mean temperature in the collector during working hours (mean value between the flow input and the flow output)

$\overline{\mathrm{T}}_{\mathrm{a}}=$ mean ambient temperature

$\overline{\mathrm{G}}=$ mean solar irradiance radiation, calculated from daily solar irradiation $\mathrm{H}$ and the theoretical number of sun hours $\mathrm{h}_{\text {sun }}$.

This model should in theory allow a better interpolation of the experimental data, as it also considers the dependence of the system's performance on ambient temperature. However, it has always produced lower correlation values than Method A, as it can be observed in Figure 4, again considering Case Study 1.

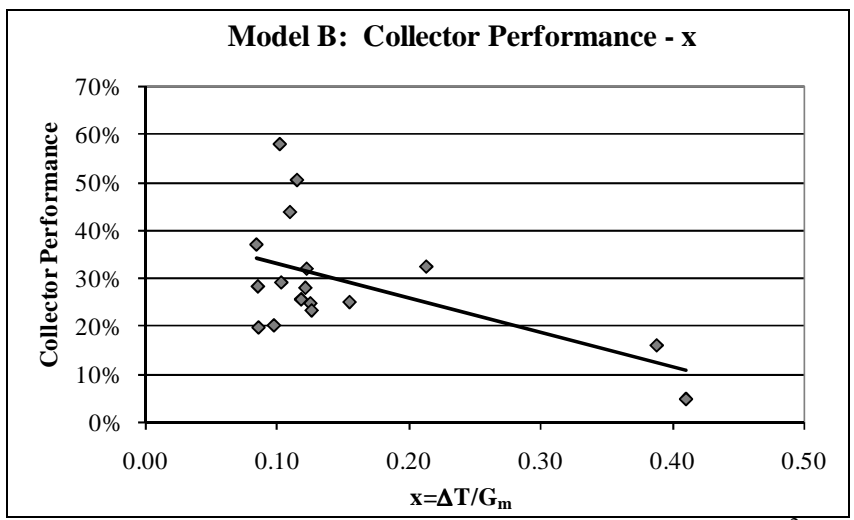

Fig. 4. Model B: Intercept $y=40.17 \%$. Slope $=-0.72 \mathrm{~W} / \mathrm{m}^{2} \mathrm{~K}$. $\mathrm{R}^{2}=0.30$

The slope of the straight line is negative as expected, but other simulations gave a positive slope, which is physically more difficult to justify. This seems an evidence that factors such as effective use of DHW and management are more important than physical factors.

\section{Modelling of the annual behaviour of the solar installations}

Once the parameters of the correlation are obtained, the equations can be extrapolated for the whole year, summing up the monthly contribution. The monthly energy available on the collectors plane has been calculated, and afterwards the monthly energy produced by using model A (3) and model B (4). 
In Figure 5 the results of both models can be observed for case 1. As it could be expected, the results obtained are very similar.

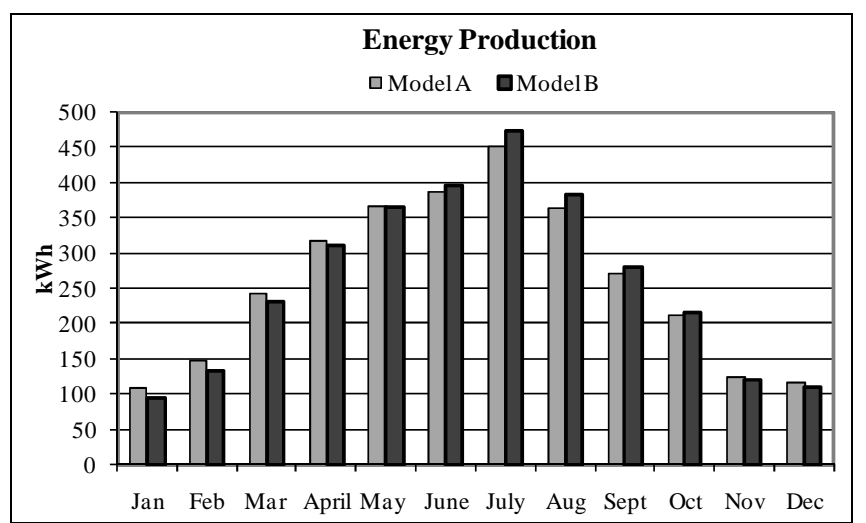

Fig. 5: Monthly simulation for the production of the SCDHW system according to models $\mathrm{A}$ and $\mathrm{B}$. (Case $\mathrm{n}^{\circ} 1$ )

\section{POLYSUN software simulation}

Solar energy production was also simulated using Polysun [4],[5]. The program provides results about the energy transferred by the collectors to the storage; in this case storage losses from the have not been considered.

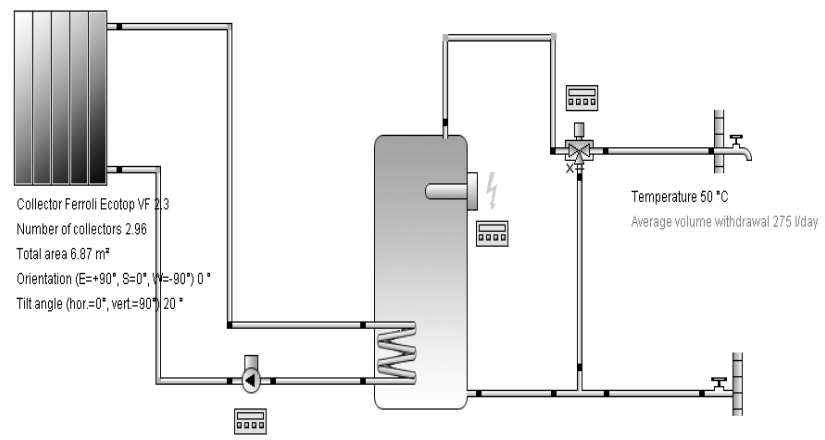

Fig. 6. Polysun System Diagram (Case $\left.{ }^{\circ} 1\right)$

For the analysis of the solar energy production, two simulation models have been defined, according to the daily need of DHW:

1. Polysun A: the daily DHW demand was assumed to be the reference value for northern of Italy of 42 1/day per $\mathrm{m}^{2}$ of solar collector [6].

2. Polysun B: the daily demand of hot water was assumed to be the one optimizing the yearly agreement between Polysun results and Model B results.

In this case the demand was always lower than the reference value above.

\section{f-Chart calculation}

Finally, the $f$-chart method [7] was used for estimating the fraction " $f$ " of the monthly total load supplied by the solar DHW system. " $f$ " is given as a function of the two nondimensional parameters $\mathrm{X}$ and $\mathrm{Y}$; the first is the ratio of collector losses to heating loads, and the second is the ratio of absorbed solar radiation to heating loads.

$\mathrm{X}=\frac{\mathrm{A}_{\mathrm{C}} \mathrm{F}_{\mathrm{R}}^{\prime} \mathrm{U}_{\mathrm{L}}\left(\mathrm{T}_{\text {ref }}-\overline{\mathrm{T}}_{\mathrm{a}}\right) \Delta \tau}{\mathrm{L}} \quad \mathrm{Y}=\frac{\mathrm{A}_{\mathrm{C}} \mathrm{F}_{\mathrm{R}}^{\prime}(\tau \alpha) \mathrm{H}_{\mathrm{T}} \mathrm{N}}{\mathrm{L}}$
Where;

$\mathrm{A}_{\mathrm{C}}=$ Total collector aperture area $\left(\mathrm{m}^{2}\right)$

$F_{R}^{\prime}=$ Whillier removal factor

$\mathrm{U}_{\mathrm{L}}=$ Collector overall loss coefficient $\left(\mathrm{W} / \mathrm{m}^{2}{ }^{\circ} \mathrm{C}\right)$

$\Delta \tau=$ Time (hours)

$\mathrm{T}_{\text {ref }}=$ Reference temperature $\left(100^{\circ} \mathrm{C}\right)$

$\overline{\mathrm{T}_{\mathrm{a}}}=$ Monthly average ambient temperature $\left({ }^{\circ} \mathrm{C}\right)$

$\tau \alpha=$ transmittance-absorptance product of the collector

$\mathrm{L}=$ Heat demand during the period $\Delta \tau(\mathrm{Wh})$

$\mathrm{H}_{\mathrm{T}}=$ Monthly average daily irradiation incident on collector surface per unit area $\left(\mathrm{Wh} / \mathrm{m}^{2}\right)$

$\mathrm{N}=$ Number of days

The factors $\mathrm{F}_{\mathrm{R}} \mathrm{U}_{\mathrm{L}}$ and $\mathrm{F}_{\mathrm{R}} \tau \alpha$ are readily available from standard collector tests. $f$ is given by the following equation:

$f=1.040 \mathrm{Y}-0.065 \mathrm{X}-0.159 \mathrm{Y}^{2}+0.00187 \mathrm{X}^{2}-0.0095 \mathrm{Y}^{3}$

A correction factor is used to correct the performance of the system according to the storage capacity as shown in eq. 9 and 10 .

$\frac{\mathrm{Xc}}{\mathrm{X}}=\left(\frac{\text { Actual storage capacity }}{\text { S tan dard storage capacity }}\right)^{-0.25}$

for $0.5 \leq\left(\frac{\text { Actual storage capacity }}{S \text { tan dard storage capacity }}\right) \leq 4.0$

Where standard storage capacity $=751 \mathrm{t} / \mathrm{m}^{2}$.

\section{Results}

The monitoring campaign has led to a number of general comments about design and management. First of all, it has shown satisfactory results in more than half the installations, although the design of the installations appears very heterogeneous and does not follow "standard" schemes, and numerous anomalies related to management and control systems have been identified.

Moreover, some collectors have been installed with an unfavorable azimuth, which may be justified in the case of tilted roofs, while there does not seem to be any apparent reason in the case of flat roofs.

In some cases the follow up and commissioning procedure has not been implemented correctly In particular, temperature sensors are often misplaced, possibly causing malfunctioning in the installations, even when the equipment is correctly controlled.

Example: a not well attached temperature probe can either activate the pump when the output temperature of the collectors is lower than the storage tank temperature, or may not activate the circulation flow when there is useful energy available at the solar collector.

The maintenance of the equipment appears adequate. Half of the installations have a heat counter in the solar circuit. Data are visible and relieved but not memorized. If an automatic record and transmission of the collector's production data to the Province of Torino were implemented, malfunctioning could be rapidly spotted without having to organize an expensive in situ follow up and control of the installations. 


\begin{tabular}{|c|c|c|l|}
\hline $\mathbf{N}^{\mathbf{0}}$ & $\begin{array}{c}\text { Orie } \\
\text { ntati } \\
\text { on }\end{array}$ & Slope & \multicolumn{1}{|c|}{ Notes: monitoring and measurement period. } \\
\hline 1 & $0^{\circ}$ & $20^{\circ}$ & $\begin{array}{l}\text { Not well attached temperature probes. High storage tank } \\
\text { temperature Excessive speed of the flow pump. }\end{array}$ \\
\hline 2 & $0^{\circ}$ & $30^{\circ}$ & $\begin{array}{l}\text { Not well attached temperature probes. High storage tank } \\
\text { temperature. }\end{array}$ \\
\hline 3 & $20^{\circ}$ & $35^{\circ}$ & Not well attached temperature probes. \\
\hline 4 & $69^{\circ}$ & $25^{\circ}$ & Incomplete insulation. \\
\hline 5 & 0 & $30^{\circ}$ & $\begin{array}{l}\text { The secondary circuit pump of the exchanger is out of } \\
\text { service. The central for the regulation of the solar system } \\
\text { does not work. Control systems to be reset }\end{array}$ \\
\hline 6 & $0^{\circ}$ & $36^{\circ}$ & $\begin{array}{l}\text { Not well attached temperature probes. High storage tank } \\
\text { temperature. }\end{array}$ \\
\hline 7 & $27^{\circ}$ & $30^{\circ}$ & $\begin{array}{l}\text { The system present problem when measuring flow. } \\
\text { Thermal system must be corrected. Not well attached } \\
\text { temperature probes. High storage tank temperature }\end{array}$ \\
\hline 8 & $0^{\circ}$ & $30^{\circ}$ & $\begin{array}{l}\text { It does not work. Old gas boiler is not integrated in the } \\
\text { system. }\end{array}$ \\
\hline 9 & $62^{\circ}$ & $45^{\circ}$ & $\begin{array}{l}\text { Not well attached temperature probes. High storage tank } \\
\text { temperature }\end{array}$ \\
\hline 10 & $0^{\circ}$ & $47^{\circ}$ & $\begin{array}{l}\text { The circulation pump works continuously. Not well } \\
\text { attached temperature probes. High temperature in the } \\
\text { second storage tank. }\end{array}$ \\
\hline
\end{tabular}

Typical results of all simulations are shown in Figures 7 and 8 , valid for case 1 .

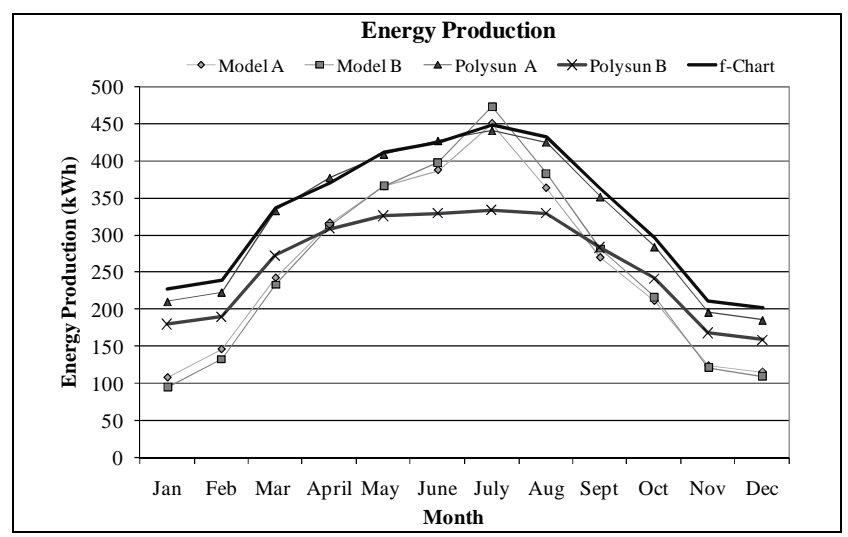

Fig. 7. Monthly simulation for the production of the collectors according to both simulation methodologies, both Polysun simulation and $f$-chart $\left(\right.$ Case $\left.n^{\circ} 1\right)$.

Looking at the overall results, it can be observed that Model A and Model B show similar results.

Another consideration is that also Polysun A and f-chart results are very similar, although this last is a method of simple and straightforward application, while Polysun takes into account many other terms, such as energy losses from piping, storage tank and control system.

Actually, Polysun $\mathrm{A}$ and $f$-chart always tend to overestimate the solar yield compared to methods A and B. This difference between $f$-chart method and Model B has a minimum value of $26.6 \%$ in case study 1 , and a maximum of $81.5 \%$ in case study 3 . The difference between Polysun A method and Model B has a minimum of $17.5 \%$, in case study 5 and a maximum of $91.9 \%$ in case study 3 .

The large difference between experimental data extrapolation through Models A and B on one side, and Polysun and $f$-chart on the other side, can be partially explained by the different solar irradiance data adopted by Polysun respect to UNI-10349, but is more likely due to the different assumptions about DHW needs. Adjusting the DHW loads to more realistic values (Polysun B) will provide annual yields which are much more consistent with measured data, although the monthly trend is not in good agreement with "experimental" data.
Table II.

\begin{tabular}{|c|c|c|c|c|c|c|c|c|c|c|}
\hline & \multicolumn{10}{|c|}{ Case Studies } \\
\hline & 1 & 2 & 3 & 4 & 5 & 6 & 7 & 8 & 9 & 10 \\
\hline & & & & & & & Energy & Produc & tion $(\mathrm{kV}$ & $\left.\mathrm{h} / \mathbf{m}^{2}\right)$ \\
\hline Model A & 471 & 404 & 448 & 374 & 405 & 482 & \begin{tabular}{|l|}
279 \\
\end{tabular} & & \begin{tabular}{|l|}
388 \\
\end{tabular} & 568 \\
\hline Model B & 474 & 399 & 432 & 340 & 555 & 411 & 401 & & 312 & 527 \\
\hline 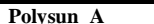 & 585 & 613 & 829 & $\begin{array}{l}439 \\
439\end{array}$ & 652 & $\begin{array}{ll}578 \\
\end{array}$ & $\begin{array}{l}559 \\
59\end{array}$ & 442 & (478 & 776 \\
\hline Polysun B & 474 & 399 & 434 & 341 & 556 & 411 & 401 & & 312 & 527 \\
\hline F-Chart & 601 & 626 & 798 & 502 & 713 & 600 & 617 & 610 & 513 & 743 \\
\hline & & & & & & & Ener: & ov Avail & able $(\mathrm{kV})$ & $\left.\mathrm{h} / \mathrm{m}^{2}\right)$ \\
\hline Irr. coll. Model & 1501 & 1538 & 1526 & 1381 & 1538 & 1544 & 1512 & & \begin{tabular}{|l|}
1355 \\
\end{tabular} & 1524 \\
\hline Irr. coll.Polysun & 1535 & 1585 & 1571 & 1375 & \begin{tabular}{|l|}
1585 \\
\end{tabular} & 1598 & 1545 & 1419 & \begin{tabular}{|l|}
1373 \\
\end{tabular} & 1588 \\
\hline
\end{tabular}

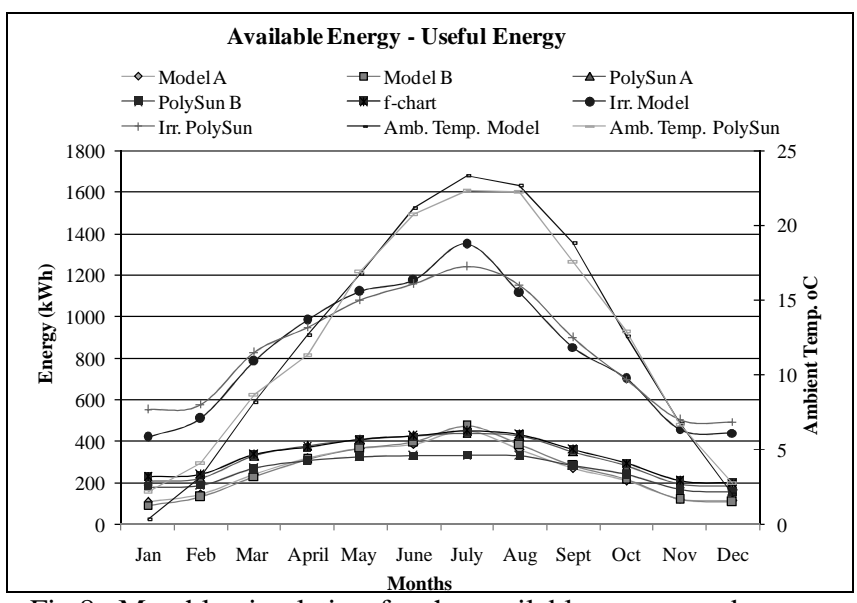

Fig.8. Monthly simulation for the available energy and energy production. (Case $\mathrm{n}^{\circ} 1$ )

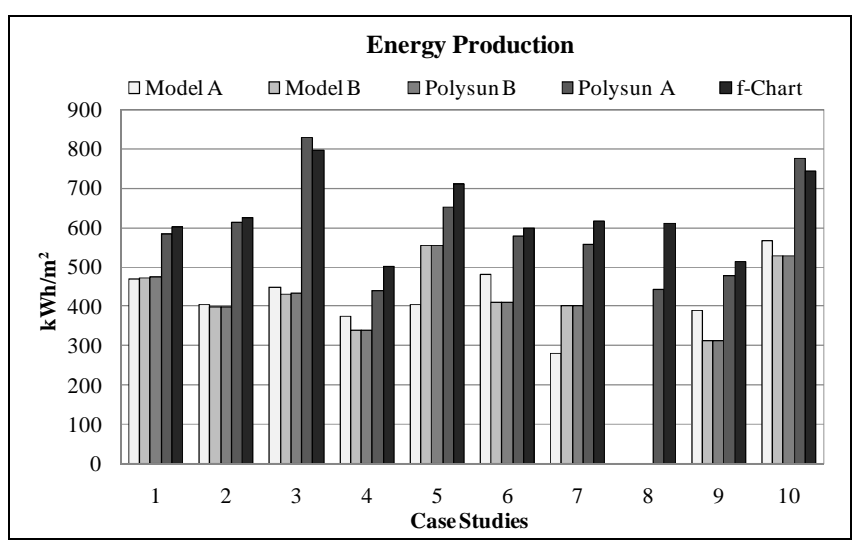

Fig. 9. Annual simulation of the energy production of the solar DHW systems according to experimental extrapolated data, Polysun simulations and $f$-chart.

\section{Conclusions}

The present work shows that a simplified inspection of SCDHW systems may reveal major causes of inefficiency, especially regarding non optimal orientation and general minor installation failures (incomplete insulation, not well attached temperature probes, control systems to be reset etc.).

When possible, data from already installed heat counter should be used, provided they are well installed and configured to properly transfer and record the data. A quick inspection will easily clarify if the heat counter is working properly.

If not, with a short measurement campaign of about twothree weeks, relevant information can be gained about the actual performance of the SCDHW system. During the measurement campaign, solar irradiance, inlet and outlet 
temperatures from the solar collector to the storage and flow rates have to be measured and sampled with appropriate time sampling (e.g., > 10'-15'),. Global horizontal irradiance may also be provided by a weather station close to the site, but it has to be recalculated according to the actual tilt and orientation of solar collectors.

In order to have a fairly reliable estimate of the yearly performance of the system, data may be gathered in daily values.

Different regression models have been used to extrapolate the daily measured data to the whole year, and in order to verify their reliability the results have been compared with commercial software, namely Polysun, and with a well known pocket calculation method (f-chart). The results are quite different, but it has been shown that the difference is probably due to different DHW needs assumed in the calculations respect to the actual situation.

Since DHW loads are not known from the measurements, simulations have been performed using standard load values of $42 \mathrm{l} /$ day per $\mathrm{m}^{2}$ of solar collector. With this assumption Polysun and $f$-chart simulations give higher values of solar production than real (from 450 to 800 $\mathrm{kWh} / \mathrm{m}^{2}$ per year, compared with measured and extrapolated data typically ranging between 350 and 500 $\mathrm{kWh} / \mathrm{m}^{2}$ ). Lower demands (25-30 1/day per $\mathrm{m}^{2}$ ) would on the opposite provide rather good agreement.

One possible conclusion is that all analysed systems are oversized respect to the actual DHW demand.

Even if a limited number of Vacuum Tube collectors have been studied, both measurements and simulations show that their production is lower than expected. A possible explanation is that real installations are not optimized for the use of this type of collectors.

In conclusion, the methodology which has been described should be integrated by a careful estimate of DHW demand. This would improve the agreement between the results of extrapolation and Polysun or $f$-chart estimates.

\section{Acknowledgements}

This work was carried out in the frame of a Provincia di Torino-Compagnia di San Paolo grant for assessment of performance of SCDHW installation in public buildings.

\section{References}

[1] Solar Thermal Markets in Europe - Trends and Market Statistics, 2010. (www.estif.org)

[2] UNI-EN 12976-1:2001. Thermal Solar Systems and Components. Factory made Systems. Part 1. General Requirements, 2001.

[3] ISO 9806-2:1995. Test methods for solar collectors. Part 2: Qualification test procedures.

[4] Polysun. User's manual for Polysun 3.3, SPF, Switzerland, 2000.
[5] Gantner M. Dynamische simulation thermischer solaranlagen. Diploma Thesis, Hochschule fur Technik Rapperswil (HSR), Switzerland, 2000.

[6] Battisti R, Calderoni M, Siciliano A. Linee Guida per la progettazione, installazione, collaudo e manutenzione di impianti solari termici. Ambiente Italia SRL, 2011.

[7] Beckman WA, Klein SA, Duffie JA. Solar heating design by the f-chart method. New York: Wiley/Interscience, 1977. 